\title{
Flocculant Based on Acrylamide and Acrylic Acid Grafted on Sodium Alginate by Electron Beam Irradiation
}

\begin{abstract}
GABRIELA CRACIUN, ELENA MANAIL A*, DANIEL IGHIGEANU
National Institute for Laser, Plasma and Radiation Physics, Electron Accelerators Laboratory, 409 Atomistilor Str.,077125, Magurele, Romania

The paper presents the obtaining, characterization and testing of a new type of polyelectrolyte based on acrylamide (2.63 mol/L), acrylic acid $(1.73 \mathrm{~mol} / \mathrm{L})$ and sodium alginate $\left(4.63 \times 10^{-3}\right.$ and $\left.9.26 \times 10^{-3} \mathrm{~mol} / \mathrm{L}\right)$, for flocculation purposes. Two types of monomeric solutions were irradiated in electron beam at room temperature and in atmospheric conditions with doses between 0.5 and $2 \mathrm{kGy}$ using ALID 7 linear electron accelerator of $5.5 \mathrm{MeV}$. The potassium persulfate $\left(9.25 \times 10^{4} \mathrm{~mol} / \mathrm{L}\right)$ was used as reaction initiator in both types of solutions. The flocculants thus obtained were characterized using various physical and chemical methods in order to determine conversion coefficient, residual monomer content, intrinsic viscosity, grafting ratio and grafting efficiency. The flocculation efficiency was evaluated in 0.1 and 0.2 wt \% blue kaolin suspension at room temperature using a standard J ar test apparatus.
\end{abstract}

Keywords: electron beam irradiation, flocculants, acrylamide, sodium alginate

Coagulation and flocculation still play a dominant role in many water and waste water treatment schemes [1], that require both inorganic and organic flocculants [2]. Among the organic type, polymeric flocculants (synthetic as well as natural) are preferred because of their low dosage, easy handling, production of large cohesive flocs and biodegradability potential. The use of flocculants having biodegradable potential in waste water and industrial effluent treatments, are justified by the actual concern for environmental degradation [2, 3]. Radiation processing offers a clean and additive-free method for the preparation of value-added novel materials based on renewable, non-toxic and biodegradable natural polymers and natural polymer waste. Past research has shown that, depending on the irradiation conditions, natural polysaccharides (alginate, chitin, chitosan, carrageeneans, carboxyl methyl cellulose, etc.) can be used. This paved the way for the development of many successful applications, some of which have been commercialized for use in agriculture, healthcare and environmental protection [4-6]. Natural polysaccharides function as bridging flocculants. It has been established that by grafting polyacrylamide branches on polysaccharides, the dangling grafted chains have easy approachability to the contaminants [2]. The goal of the paper is to present the obtaining, characterization and testing of a new type of polyelectrolyte obtained by electron beam irradiation, for flocculation purposes. The polyelectrolyte, based on acrylamide, acrylic acid and sodium alginate, was characterized from the chemical and physical point of view. Flocculation efficiency was also evaluated in 0.1 and 0.2 wt \% blue kaolin suspension.

\section{Experimental part}

Materials

Acrylamide (AMD) (min $99 \%$ purity, molar mass 71.08 $\mathrm{g} / \mathrm{mol}$, density $1.13 \mathrm{~g} / \mathrm{cm}^{3}$, solubility in water $2.04 \mathrm{~kg} / \mathrm{L}$ at $25^{\circ} \mathrm{C}$ ), acrylic acid (AA) ( $\min 99 \%$ purity, molar mass 72.06 $\mathrm{g} / \mathrm{mol}$, density $1.051 \mathrm{~g} / \mathrm{cm}^{3}$, solubility in water: miscible, viscosity $1.3 \mathrm{CP}$ at $20^{\circ} \mathrm{C}$ ), sodium alginate (Alg) (molecular weight $216.121 \mathrm{~g} / \mathrm{mol}$, density $1.601 \mathrm{~g} / \mathrm{cm}^{3}$, solubility in water; no more than $2 \%$ on the dried basis), potassium persulfate (I) (min $99 \%$ purity, molar mass $270.322 \mathrm{~g} / \mathrm{mol}$, density $2.477 \mathrm{~g} / \mathrm{cm}^{3}$, solubility in water $5.29 \mathrm{~g} / 100 \mathrm{~mL}$ at $20^{\circ} \mathrm{C}$ ) were obtained from LACHEMA, Germany, and used directly, without purification.

\section{Sample preparation}

For the polyelectrolytes obtaining, two types of monomeric solutions were used as fallows: Sol I (AMDAA/Alg I) containing sodium alginate $4.63 \times 10^{-3} \mathrm{~mol} / \mathrm{L}$, acrylamide $2.63 \mathrm{~mol} / \mathrm{L}$, acrylic acid $1.73 \mathrm{~mol} / \mathrm{L}$ and Sol II (AMD-AA/Alg II) containing sodium alginate $9.26 \times 10^{-3} \mathrm{~mol}$ /L, acrylamide $2.63 \mathrm{~mol} / \mathrm{L}$, acrylic acid $1.73 \mathrm{~mol} / \mathrm{L}$. In both of them, $9.25 \times 10^{-4} \mathrm{~mol} / \mathrm{L}$ of potassium persulfate was added as reaction initiator.

\section{Experimental installations and flocculants synthesis}

The irradiation of Sol I and Sol II was performed using the ALID 7 linear electron accelerator of travelling-wave type built in the National Institute for Laser, Plasma and Radiation Physics, with the following characteristics: 5.5 $\mathrm{MeV}$ electron beam (EB) energy, $130 \mathrm{~mA}$ peak current, 3.75 is pulse duration, $134 \mathrm{~W}$ maximum output power at $50 \mathrm{~Hz}$ pulse repetition frequency. The EB effects are related with the precise control of absorbed dose (D) and absorbed dose rate $\left(D^{*}\right)$ [7-9]. In experiments the electron beam dose rate was fixed at $2 \mathrm{kGy} / \mathrm{min}$ in order to accumulate doses between $0.5 \mathrm{kGy}$ and $2 \mathrm{kGy}$. The absorbed dose was determined using the graphite calorimeter. In order to assure equal doses at the entry and at the exit of the irradiated sample, the electron beam penetration depth in the sample was calculated as being $20 \mathrm{~mm}$ [9]. $15 \mathrm{~mL}$ from each monomeric solution (Sol I and Sol II) have been distributed for irradiation in polyvinylchloride (PVC) containers of $3 \mathrm{~cm}$ diameter [10]. Details concerning chemical composition and irradiation dose are presented in table 1.

\section{Purification of the grafted polymers}

Purification of the grafted polymers was realized in order to remove the homopolymer $[9,11]$ and to separate the unreacted monomers from the grafted polymers. Different concentrations of polymerized mixtures from each sample

\footnotetext{
* email: elena.manaila@inflpr.ro
} 
Table 1

THE POLYELECTROLYTES CHEMICAL COMPOSITION AND SYNTHESIS DETAILS

\begin{tabular}{|c|c|c|c|c|c|c|}
\hline \multirow[t]{2}{*}{ Samples codes } & \multirow{2}{*}{$\begin{array}{l}\text { Solutions } \\
\text { codes }\end{array}$} & \multicolumn{4}{|c|}{ Amount of chemicals (mol/L) } & \multirow{2}{*}{$\begin{array}{l}\text { Irradiation } \\
\text { dose (kGy) }\end{array}$} \\
\hline & & $\overline{\mathrm{AMD}}$ & $\overline{\mathrm{AA}}$ & Alg & $\overline{\mathrm{PP}}$ & \\
\hline AMD-AA/Alg L/0.5 & \multirow{7}{*}{ Sol I } & \multirow{7}{*}{2.63} & \multirow{7}{*}{1.73} & \multirow{7}{*}{$4.63 \times 10^{-3}$} & \multirow{7}{*}{$9.25 \times 10^{-4}$} & 0.5 \\
\hline $\mathrm{AMD}-\mathrm{AA} / \mathrm{Alg} \mathrm{I} / 0.75^{\circ}$ & & & & & & 0.75 \\
\hline AMD-AAJAI I 1.0 & & & & & & $1.0^{-}$ \\
\hline AMD-AA/Alg I/1.25 & & & & & & 1.25 \\
\hline AMD-AA/AIg I/5 & & & & & & 1.5 \\
\hline AMD-AA/Alg I/1.75 & & & & & & 1.75 \\
\hline AMD-AA/AI I/2.0 & & & & & & 2.0 \\
\hline AMD-AA/Alg II/ 0.5 & \multirow{7}{*}{ Sol II } & \multirow{7}{*}{2.63} & \multirow{7}{*}{1.73} & \multirow{7}{*}{$9.26 \times 10^{-3}$} & \multirow{7}{*}{$9.25 \times 10^{-4}$} & 0.5 \\
\hline AMD-AA/Alg II 0.75 & & & & & & $0.75^{-}$ \\
\hline AMD-AA/AIg II $1.0^{-}$ & & & & & & $1.0^{-}$ \\
\hline AMD-AA/AIg II 1.25 & & & & & & 1.25 \\
\hline $\mathrm{AMD}-\mathrm{AA} / \mathrm{AI} \mathrm{II} / 1.5$ & & & & & & 1.5 \\
\hline AMD-AA/Alg II/1.75 & & & & & & $1.75^{-}$ \\
\hline $\mathrm{AMD}-\mathrm{AA} / \mathrm{Alg} \mathrm{II} / 20^{\circ}$ & & & & & & $2.0^{-}$ \\
\hline
\end{tabular}

were completely diluted in water, then added dropwise into a large excess of methanol $(250 \mathrm{ml})$ in order to remove the homopolymer. The precipitated polymer was ûltered off and washed with methanol for 10 times $[9,11]$. Afterwards, it was precipitated by adding $250 \mathrm{~mL}$ of acetone in order to separate the unreacted monomer (acrylamide) from the grafted polymer and finally it was dried in a hot air oven at $60^{\circ} \mathrm{C}$ for $6 \mathrm{~h}$. The grafting ratio (GR, $\%)$ and grafting efficiency (GE, \%) were calculated using the following relations [9, 12-14]:

$$
\begin{aligned}
& G R(\%)=\frac{w t_{\cdot G P}-w t_{A 1 \mathrm{~g}}}{w t_{\cdot A 1 \mathrm{~g}}} \times 100 \\
& G E(\%)=\frac{w t_{\cdot G P}-w t_{\cdot A 1 \mathrm{~g}}}{w t_{\cdot M}} \times 100
\end{aligned}
$$

where $w t_{{ }_{G P^{\prime}}} w t_{\text {Alq }^{\prime}} w t_{\text {M }^{\prime}}$ are weights of the grafted polymer, sodium alginate and monomers (acrylamide and acrylic acid).

\section{Physico-chemical characteristics}

For determining the conversion coefficient of monomers $\left(C_{C}\right)$ and the residual monomer concentration $\left(M_{r}\right), 2$ grams from each polymer types were placed in $200 \mathrm{ml}$ distilled water for 24 hours, than stirred for $1 \mathrm{~h}$ at $400 \mathrm{rpm}$ for a very well mixing. $C_{c}$ and $M_{r}$ were determined by titrimetric method in which bromine reacts with the double bond of residual monomer. After complete dissolution in water, the polymers were treated excessively with a bromidebromate solution and the bromine excess was determined by means of the iodatometrymethod in presence of sodium thiosulfate solution (1 M) [9, 15-17]. The intrinsic viscosity $\left(h_{\text {intr }}\right)$ was determined using the falling ball Hoppler viscometer of $\mathrm{BH}-2$ type $[9,17]$. The measured parameter is the ball falling time in the cylindrical tube inclined with 10 degree against the vertical plane and filled with the liquid to be analyzed. The ball falling time through the polymeric solution was measured in five different concentrations. The working temperature was $30^{\circ} \mathrm{C}$ and sodium nitrate $1 \mathrm{~N}\left(\mathrm{NaNO}_{3}\right)$ was used as solvent.

\section{Fourier Transform Infrared Spectroscopy (FTIR)}

The polyelectrolyte chemical structure was investigated using a spectrophotometer Perkin Elmer-Spectrum 100 instrument equipped with ATR diamond crystal plate. Spectra were acquired in ATR mode and each spectrum consisted of 20 scans per sample, in the wavenumbers range between 4000 and $600 \mathrm{~cm}^{-1}$ with a resolution of 4 $\mathrm{cm}^{-1}$. The registered FTIR spectra were processed by applying normalization and ATR correction available on the Spectrum v.6.3.2 software.

\section{Flocculation studies}

The flocculation studies were carried out on blue kaolin suspension ( $0.1 \mathrm{wt} \%$ and $0.2 \mathrm{wt} \%$ ) at room temperature of $20^{\circ} \mathrm{C}$ to $25^{\circ} \mathrm{C}$ using the standard Jar test apparatus of Velp FC 6S type having 6 stirrer blades. In each beaker, 500 $\mathrm{mL}$ of kaolin suspension was taken and placed on the flocculator. Under a slow stirring condition, the polymer solution in concentrations of $1 \mathrm{ppm}$ to $10 \mathrm{ppm}$ was added by means of a pipette in order to determine the polymer concentration influence. The experiments were carried out at $90 \mathrm{rpm}$ for $15 \mathrm{~min}$. Clear supernatant was drawn from the top layer (up to depth $1-2 \mathrm{~cm}$ ) and its transmittance was measured at $620 \mathrm{~nm}$ using the Cary Bio-100 UV-Vis spectrophotometer.

\section{Results and discussions}

\section{Grafting ratio and grafting efficiency}

The two types of polyelectrolytes, called from now forward type I and type II, were obtained by electron beam irradiation in atmospheric conditions at room temperature of $25^{\circ} \mathrm{C}$, from the monomeric solutions having the compositions described below (Sol I and Sol II). Keeping the dose rate at $2 \mathrm{kGy} / \mathrm{min}$ and varying the irradiation dose between $0.5 \mathrm{kGy}$ and $2 \mathrm{kGy}$, were obtained polymers having various grades of grafting. The acrylamide and acrylic acid grafted on the sodium alginate backbone were evaluated through the grafting ratio (GR) and grafting efficiency (GE) expressed in \% and the results are presented in figures 1 and 2.

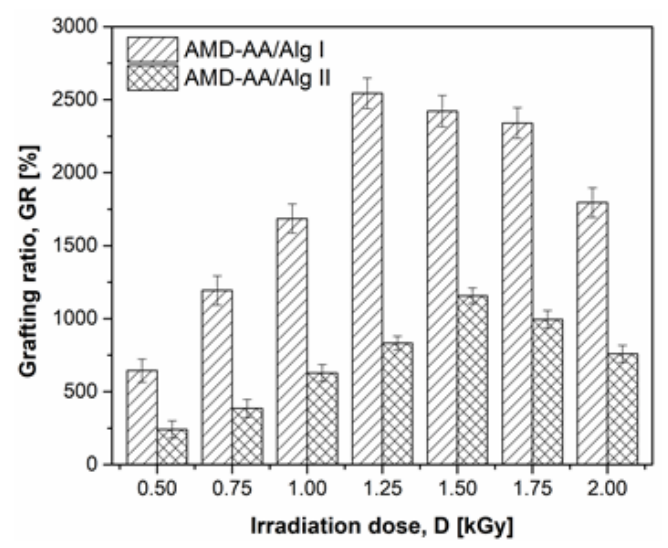

Fig 1. The grafting ratio (GR) versus the electron beam irradiation dose for AMD-AA/Alg I and AMD-AA/Alg II polymer types 


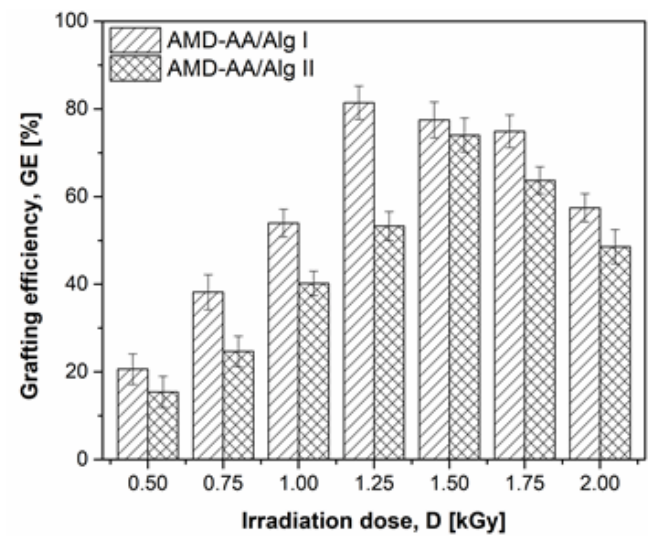

Fig 2. The grafting efficiency (GE) versus the electron beam irradiation dose for AMD-AA/Alg I and AMD-AA/Alg II polymer types

In figures 1 and 2 it can be seen that both GR and GE have increases with increasing of the irradiation dose, obtaining the maximum values of $2500 \%$ (GR) and $80 \%$ (GE) at the irradiation dose of $1.25 \mathrm{kGy}$ for polymers of type I (AMD-AA/Alg I) and of $1100 \%$ (GR) and $78 \%$ (GE) at $1.5 \mathrm{kGy}$ for polymers of type II (AMD-AA/Alg II), respectively. As the irradiation dose increased, both GR and GE decreased. But, while GR was very sensitive on both polymer type and irradiation dose, GE was less sensitive to the polymer type. Low values of GE obtained at the irradiation doses up to $1.25 \mathrm{kGy}$ and $1.5 \mathrm{kGy}$ respectively, are directly connected with the presence of high amounts of homopolymer in the system $[9,11,16]$.

\section{Physico-chemical characteristics}

For the grafted polymers obtained as above, were determined the conversion coefficient (CC), residual monomer concentration $\left(M_{r}\right)$ and intrinsic viscosity $\left(h_{i n t}\right)$. In table 2 it can be seen that for both types of polymers, AMD-AA/ALg I and AMD-AA/ALg II, high conversion coefficients (up to $97 \%$ approximately) are correlated with low residual monomers contents (under $0.02 \%$ ) as the radiation dose increased.

In radiation processing, the probability of a higher molecular contact is increased by the irradiation dose increasing, resulting in the propagation of active chain and continuously $C_{\text {increase }}[9,18,19]$. For both $C_{\text {c }}$ and $M_{\text {it }}$ it cannot be observed notable differences between the samples having different initial concentrations of sodium alginate irradiated at the same dose. The highest levels of

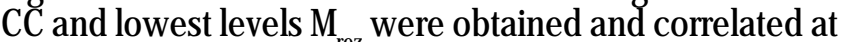
the irradiation dose of 1 ro $5 \mathrm{kGy}$ and $2 \mathrm{kGy}$. The only physical parameter affected by the irradiation dose increasing was $\eta_{\text {int }}$ It increased up to $1.04 \mathrm{dL} / \mathrm{g}$ at the irradiation dose of 1 $\mathrm{kGy}$, then decreases up to $0.58 \mathrm{dl} / \mathrm{g}$ for the polymer of type I. The polymers of type II did not show intrinsic viscosities over $1 \mathrm{dL} / \mathrm{g}$ at any irradiation dose. The effect of sodium alginate concentration and irradiation dose on the grafting reaction was investigated and then correlated with the FTIR analysis.
Fourier Transform Infrared Spectroscopy (FTIR)

In order to evaluate the binding of acrylamide and acrylic acid on the sodium alginate backbone, the infrared spectra of the grafted polymers was performed. Infigures 3-6 are presented the spectra of AMD-AA/ALg I/ and AMD-AA/ALg

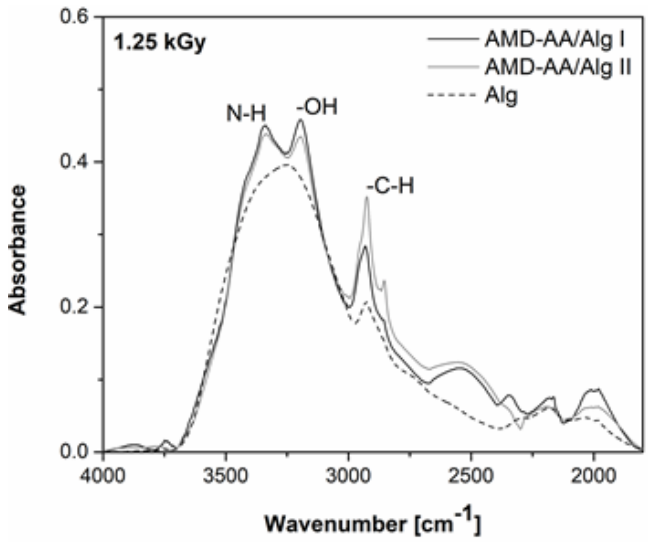

Fig. 3. The FTIR spectra of AMD-AA/Alg I and AMD-AA/Alg II obtained at $1.25 \mathrm{kGy}$ between $4000-2000 \mathrm{~cm}^{-1}$

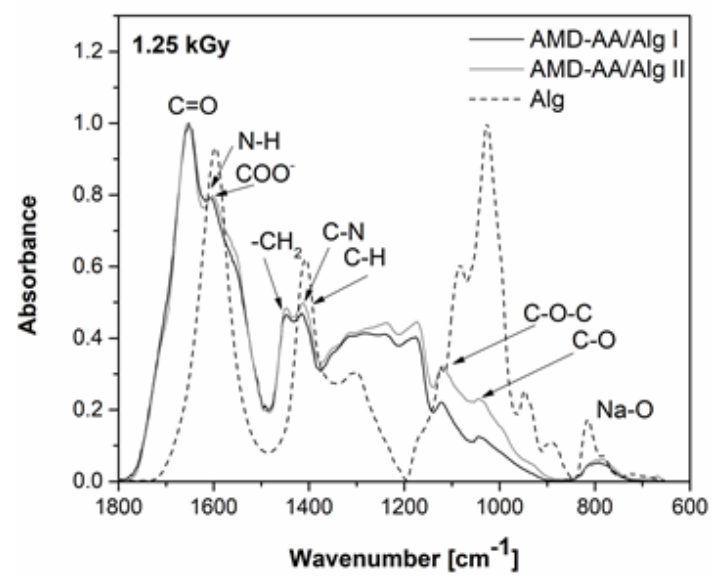

Fig. 4. The FTIR spectra of AMD-AA/Alg I and AMD-AA/Alg II obtained at $1.25 \mathrm{kGy}$ between $1800-650 \mathrm{~cm}^{-1}$

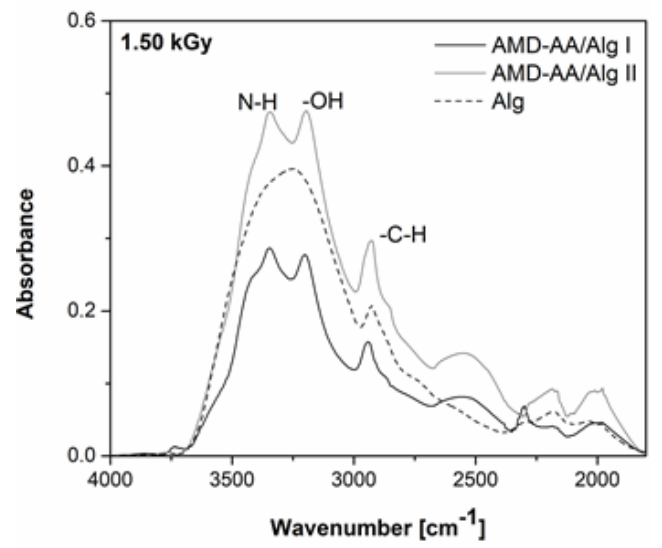

Fig. 5. The FTIR spectra of AMD-AA/Alg I and AMD-AA/Alg II obtained at $1.50 \mathrm{kGy}$ between $4000-2000 \mathrm{~cm}^{-1}$

\begin{tabular}{|c|c|c|c|c|c|c|c|}
\hline & \multicolumn{7}{|c|}{ Irradiation dose (kGy) } \\
\hline & 0.5 & 0.75 & 1.0 & 1.25 & 1.5 & 1.75 & 2.0 \\
\hline & \multicolumn{7}{|c|}{ Conversion coefficient, $\mathrm{C}_{\mathrm{c}}(\%)$} \\
\hline AMD-AA/Alg I & 82.33 & 83.05 & 89.99 & 95.63 & 96.84 & 98.01 & 97.99 \\
\hline \multirow[t]{2}{*}{ AMD-AA/Alg II } & 82.34 & 87.26 & 90.22 & 96.12 & 97.08 & 97.34 & 97.87 \\
\hline & \multicolumn{7}{|c|}{ Intrinsic viscosities $\eta_{\text {intr. }}(\mathrm{dl} / \mathrm{g})$} \\
\hline AMD-AA/Alg I & 0.90 & 0.92 & 1.04 & 1.03 & 1.01 & 0.64 & 0.58 \\
\hline \multirow[t]{2}{*}{$\mathrm{AMD}-\mathrm{AA} / \mathrm{Alg} \mathrm{II}$} & 0.51 & $0.72^{-}$ & 0.77 & 0.92 & 0.91 & $0.70^{-}$ & 0.61 \\
\hline & \multicolumn{7}{|c|}{ Residual monomers contents $\mathbf{M}_{\text {rez. }}(\%)$} \\
\hline AMD-AA/Alg I & $\overline{0.114}$ & 0.109 & 0.068 & 0.027 & 0.020 & 0.014 & $\overline{0.014}$ \\
\hline AMD-AA/Alg II & 0.112 & 0.082 & 0.063 & 0.024 & 0.019 & 0.017 & 0.014 \\
\hline
\end{tabular}

Table 2

PHYSICAL AND CHEMICAL CHARACTERISTICS $\left(C_{C}, C_{\text {intr. }} M_{\text {rez. }}\right)$ OF THE POLYMERS 


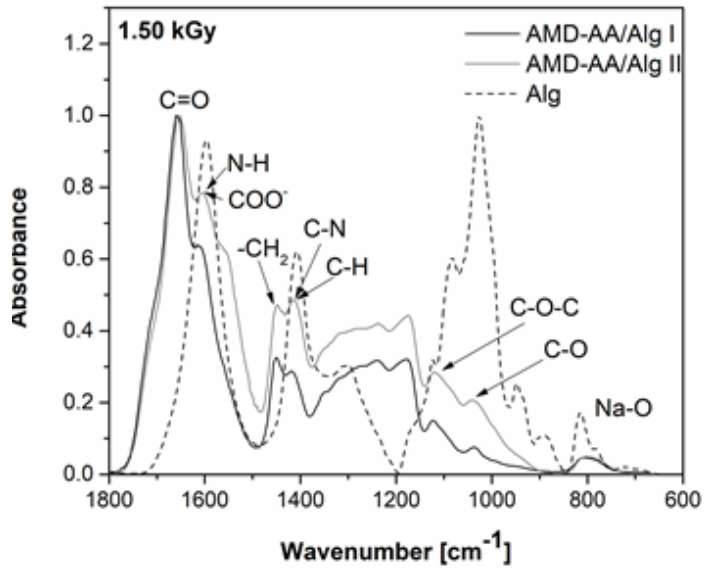

Fig. 6. The FTIR spectra of AMD-AA/Alg I and AMD-AA/Alg II obtained at $1.50 \mathrm{kGy}$ between $1800-650 \mathrm{~cm}^{-1}$

II/ samples irradiated at 1.25 and $1.5 \mathrm{kGy}$ on two spectral intervals $\left(4000-2000 \mathrm{~cm}^{-1}\right.$ and $\left.1800-650 \mathrm{~cm}^{-1}\right)$.

The band near $3100 \mathrm{~cm}^{-1}$ that correspond to the stretching vibration of $-\mathrm{OH}$ groups of sodium alginate [2022] can be seen in both AMD-AA/ALg I and AMD-AA/ALg II spectra obtained at $1.25 \mathrm{kGy}$ (fig. 3) and $1.5 \mathrm{kGy}$ also (fig. $5)$. On this band, there are observed modifications in absorbance for samples obtained at the same irradiation dose as a function of sodium alginate concentration. Samples obtained at the irradiation dose of $1.5 \mathrm{kGy}$ present significant differences in absorbance compared to those obtained at $1.25 \mathrm{kGy}$. The variation in intensity and the shifted appearance at $3192 \mathrm{~cm}^{-1}$, indicates the partially participation of hydroxyl groups in chemical reaction [21]. A decreasing of intensity in the case of AMD-AA/ALg II samples indicates that, by doubling the sodium alginate concentration in the irradiated samples, the grafting reaction was affected [22]. The sharp bands around 1620 $\mathrm{cm}^{-1}$ are attributed to the asymmetric $\mathrm{COO}$ - stretching (figs. 4 and 6). The bands around $1417 \mathrm{~cm}^{-1}$ (figs. 4 and 6) correspond to the $\mathrm{C}$-H deformation with secondaryalcohols [22]. Finally, the bands around $1120 \mathrm{~cm}^{-1}, 1093 \mathrm{~cm}^{-1}$ and $1031 \mathrm{~cm}^{-1}$ are due to the asymmetric C-O-C stretching, C$\mathrm{O}$ stretching in $\mathrm{CH}-\mathrm{OH}$ structure and symmetric $\mathrm{C}-\mathrm{O}$ stretching in $\mathrm{C}-\mathrm{O}-\mathrm{C}$ structure, respectively (figs. 4 and 6 ) [22].

The bands at $3360 \mathrm{~cm}^{-1}$ and $1320 \mathrm{~cm}^{-1}$ are usually attributed to the stretching vibration of $\mathrm{N}-\mathrm{H}$ [22] and we found them slightly shifted at $3335 \mathrm{~cm}^{-1}$ and $1321 \mathrm{~cm}^{-1}$, respectively. Same situation was met in the case of band corresponding to the $\mathrm{C}=0$ stretching (around $1651 \mathrm{~cm}^{-1}$ instead of $1670 \mathrm{~cm}^{-1}$ ). The bands corresponding to the $\mathrm{N}-\mathrm{H}$

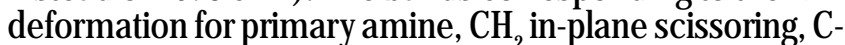
$\mathrm{N}$ stretching for primary amide, $\mathrm{C}-\mathrm{H}^{2}$ deformation and $\mathrm{NH} 2$ in-plane rocking were found at $1621 \mathrm{~cm}^{-1}, 1448 \mathrm{~cm}^{-1}, 1417$ $1415 \mathrm{~cm}^{-1}, 1349 \mathrm{~cm}^{-1}$ and $1122 \mathrm{~cm}^{-1}$, respectively.

\section{Flocculation studies}

Grafted polymers characterized as above were used in flocculation studies that were carried out on blue kaolin suspension at room temperature of $25^{\circ} \mathrm{C}$. Were studied the influence of kaolin concentration $(0.1 \mathrm{wt} \%$ and $0.2 \mathrm{wt}$ $\%$ ), polymer concentration (from $0.5 \mathrm{ppm}$ to $5 \mathrm{ppm}$ ) and rotation speed (from $60 \mathrm{rpm}$ to $90 \mathrm{rpm}$ ) on flocculation efficacy in terms of transmittance against distilled water.

For the first experiments set, in the Jar test glass bakers filled with $500 \mathrm{~mL}$ kaolin suspension of 0.1 wt $\%$ and 0.2 wt \%, were added polyelectrolytes of AMD-AA/ALg I and AMD-AA/ALg II types (obtained at 1.25 and $1.5 \mathrm{kGy}$ ) in different concentrations between $0.5 \mathrm{ppm}$ and $5 \mathrm{ppm}$.
Samples were stirred first at $60 \mathrm{rpm}$ for $15 \mathrm{~min}$, then left to rest for another 15 min before sampling for analysis from the top layer clear supernatant. The results are presented in figures 7 and 8.

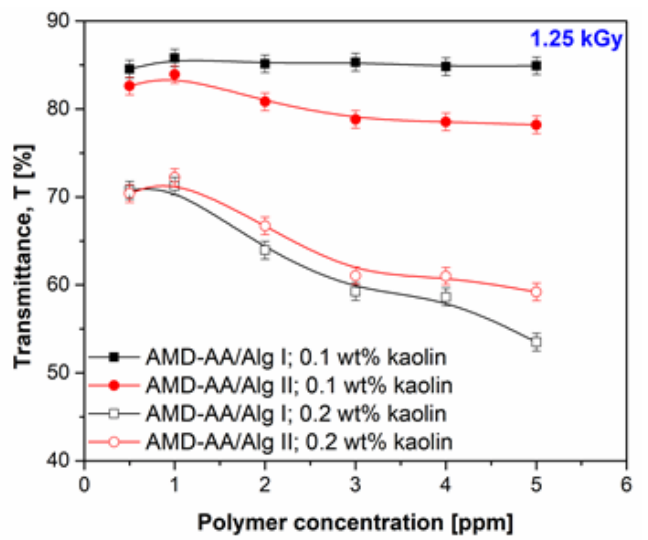

Fig. 7. The influence of the polymers (AMD-AA/Alg I and AMDAA/Alg II) obtained at $1.25 \mathrm{kGy}$ on the kaolin concentration (rotation speed: $60 \mathrm{rmp}$ )

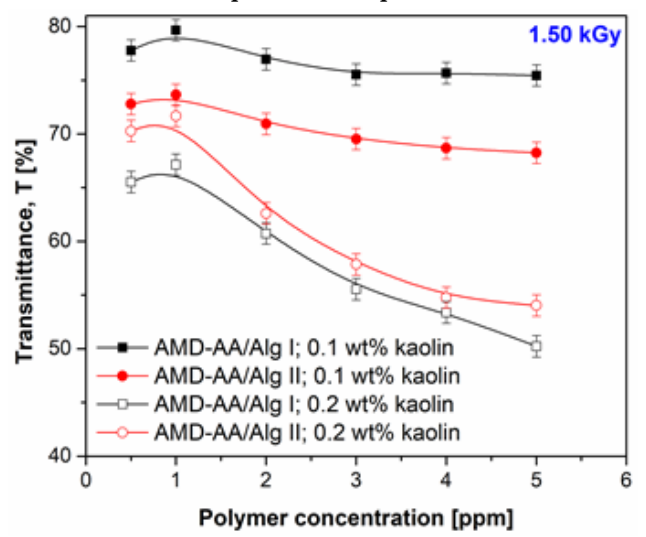

Fig 8. The influence of the polymers (AMD-AA/Alg I and AMD-AA/ Alg II) obtained at $1.50 \mathrm{kGy}$ on the kaolin concentration (rotation speed: $60 \mathrm{rmp}$ )

In the experiments that were made on kaolin suspension of $0.1 \mathrm{wt} \%$, the polymers of AMD-AA/Alg I type obtained at $1.25 \mathrm{kGy}$ have lead to a transmittances over $85 \%$ (fig. 7) while the polymers of both types obtained at $1.5 \mathrm{kGy}$, have lead to a transmittances under $80 \%$ but not less than $70 \%$ (fig. 8). Itcan be observed that the increasing of the polymer concentration leads to a slowly decreases of the transmittance, excepting the case of the AMD-AA/ Alg I type obtained at $1.25 \mathrm{kGy}$.

In the experiments that were made on kaolin suspension of $0.2 \mathrm{wt} \%$, irrespective of the irradiation dose ( $1.25 \mathrm{kGy}$ or $1.5 \mathrm{kGy}$ ) and polymer type or concentration, the transmittances were under $70 \%$. We can even see the abrupt decrease of the transmittance with the polymer concentration, in the case of the polymers obtained at the irradiation dose of $1.5 \mathrm{kGy}$ (fig. 8).

For the second experiments set, the influence of the rotation speed of the stirrer blades (between 60 and 150 rpm) was investigated on the kaolin suspension of $0.1 \mathrm{wt}$ $\%$ using the same polymers (having the best intrinsic viscosities, grafting degrees and grafting efficiencies) as in the previews experiments, in the concentrations of 0.5 ppm and $1 \mathrm{ppm}$. The results are presented in figures 9 and 10.

It can be seen that the increasing of the rotation speed of the stirrer blades over $90 \mathrm{rpm}$ leads to the increasing of all transmittances over $80 \%$ (figs. 9 and 10), reaching even up to $95 \%$ in the case of AMD-AA/Alg II, obtained at 1.25 kGy used in the concentration of $1 \mathrm{ppm}$ at a rotation speed of 150 ppm (fig. 10). 


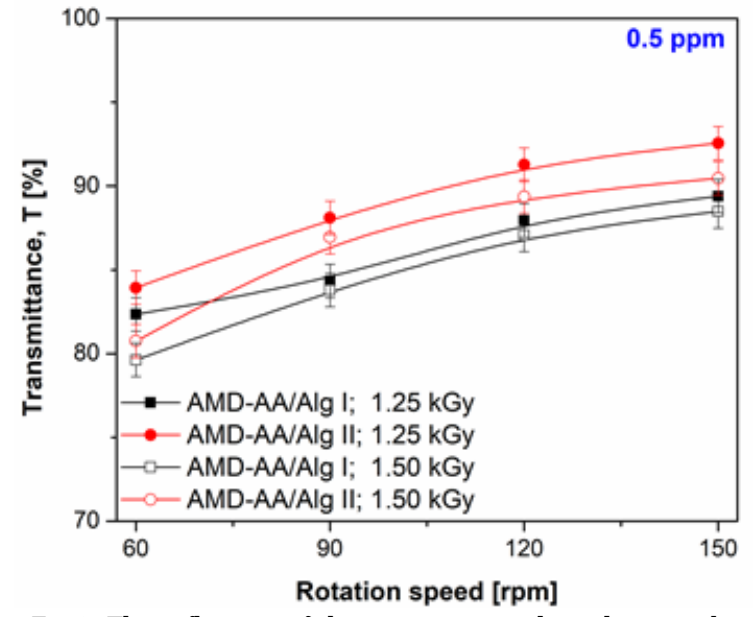

Fig 9. The influence of the rotation speed on the samples transmittance (polymer concentration: $0.5 \mathrm{ppm}$; kaolin concentration $0.1 \mathrm{wt} \%$ )

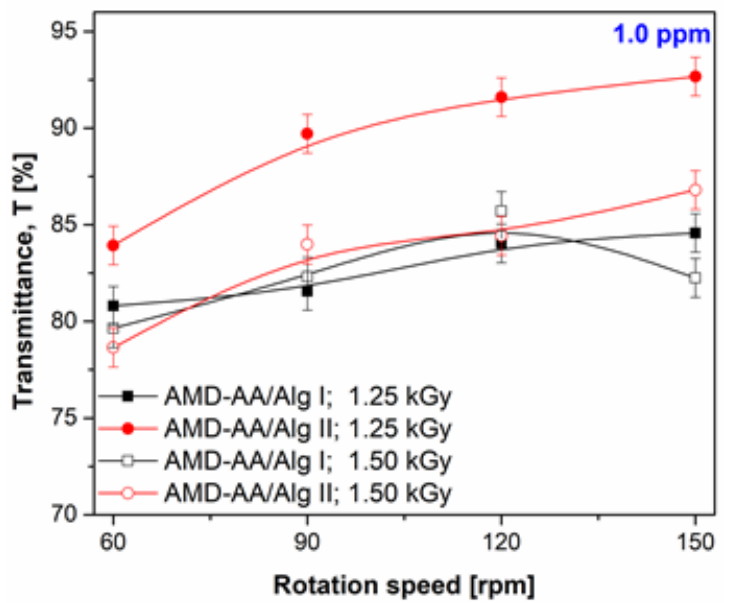

Fig 10. The influence of the rotation speed on the samples transmittance (polymer concentration: 1.0 ppm, kaolin concentration $0.1 \mathrm{wt} \%$ )

In figsures 7-10, it can be seen that both polymer types are effective in small concentrations ( $0.5 \mathrm{ppm}$ and $1 \mathrm{ppm}$ ) on both kaolin suspension of $0.1 \mathrm{wt} \%$ and $0.2 \mathrm{wt} \%$. If the polymer concentration increased, only the polymers containing the smaller amount of sodium alginate (AMD$\mathrm{AA} / \mathrm{Alg}$ I) still remain effective when it was used on the kaolin suspension of $0.1 \%$ at the rotation speed of the stirrer blades of $60 \mathrm{rpm}$. If the polymer concentration was maintained at $1 \mathrm{ppm}$, only the polymers containing the bigger amount of sodium alginate (AMD-AA/Alg II) reached the transmittance over $90 \%$ at the rotation speed of the stirrer blades of $150 \mathrm{rpm}$.

\section{Conclusions}

A new type of polyelectrolyte based on acrylamide, acrylic acid and sodium alginate for flocculation purposes was obtained by electron beam irradiation. FTIR analysis showed the grafting of acrylamide and acrylic acid on sodium alginate backbone. The grafting efficiency of acrylamide and acrylic acid on sodium alginate increases with increasing of the absorbed dose and the maximum values were obtained around $1.25 \mathrm{kGy}$. Even if the addition of a double quantity of sodium alginate did not significantly modify the conversion coefficient and residual monomer concentration, the flocculation studies that were performed on blue kaolin suspension of 0.1 wt $\%$ and 0.2 wt $\%$ presented significant differences between the transmittances. The polymers concentration and rotation speed of the stirrer blades influence on the transmittance showed the effectiveness of both polymer types in proper conditions. Modest values of intrinsic viscosities were associated, in terms of transmittance, with flocculation efficiencies up to $90 \%$.

Acknowledgements: This research was funded by Romanian Ministry of National Education and Scientific Research through Nucleu LAPLAS VI Program, contract no. 16N/08.02.2019.

\section{References}

1. BRATBY, J., Coagulation and Flocculation in Water and Wastewater Treatment, 2nd Edition, IWA Publishing Alliance House, London, 2006 p.5.

2. SINGH, R.P., TRIPATHY, T., KARMAKAR, G.P., RATH, S.K., KARMAKAR, N.C., PANDEY, S.R., KANNAN, K., JAIN, S.K., LAN, N.T., Curr. Sci. India. 78, nr. 7, 2000, p. 798.

3. CRACIUN, G., MANAILA, E., MARTIN, D., TOADER, D., IGHIGEANU, D., Mat. Plast., 48, nr. 2, 2011, p. 183.

4. *** IAEA-TECDOC-1422 - Radiation Processing of Polysaccharides, IAEA Publications, Vienna 2004

5.*** IAEA Report of the 2nd RCM on Development of radiationprocessed products of natural polymers for application in agriculture, healthcare, industry and environment, IAEA Publications, Vienna, 2010.

6. AL-ASSAF, S., The Radiation Chemistry of Polysaccharides, IAEA Publications, Eds. S. Al-Assaf, X. Coqueret, K.Z.H.M. Dahlan, M. Sen, P. Ulanski, Vienna, 2016, p. 5.

7. FITI, M., Dozimetria chimica a radiatiilor ionizante (Ionizing Radiation Chemical Dosimetry), Editura Academiei Republicii Socialiste Romania Pub., Bucuresti, 1973, p. 27.

8. NEMTANU, M., BRASOVEANU, M., Starch, 69, nr. 3-4, 2017, p. 1600027. 9. CRACIUN, G., MANAILA, E., NICULESCU, M., IGHIGEANU, D., Polym. Bull., 74, nr. 4, 2017, p. 1299.

10. STELESCU M.D., NICULESCU-ARON I.G., MANAILA E., Mat. Plast., 46, nr. 1, 2009, p. 48.

11. CAULFIELD, M.J., HAO, X., QIAO, G.G., SOLOMON, D.H., Polymer, 44, nr. 5, 2003, p. 1331.

12. SARKAR, A.K., MANDRE, N.R., PANDA, A.B., PAL, S., Carbohyd. Polym., 95, nr. 2, 2013, p. 753.

13. GHOSH, S., SEN, G., JHA, U., PAL, S., Bioresource. Technol., 101, nr. 24, 2010, p. 9638.

14. ZHANG, S., WANG, W., WANG, H., QI, W., YUE, L., YE, Q., Carbohyd. Polym. 101, 2014, p. 798.

15. CAULFIELD, M.J., HAO, X., QIAO, G.G., SOLOMON, D.H., Polymer, 44, nr. 14, 2003, p. 3817

16. SELVAPATHY, P., REDDY, M.J., Water Supply, 10, nr. 4, 1992, p. 175. 17. DIMONIE, M., BOGHINA, C., CINCU, C., MARINESCU, M., MARINESCU, N., Poliacrilamida, 1stEdition, Editura Tehnica, Bucuresti, 1986; p. 194.

18. KUMAR, D.D., PANDEY, J., RAJ , V., KUMAR, P., Open Med. Chem. J., 11, 2017, p. 109.

19. SMETS, G., DYSSELEER, E., Macromol. Chem. Phys., 91, 1966, p. 160.

20. SADEGHI, M., GODARZI, A., KHANI, F., MIRDARIKVANDE, S., SADEGHI, H., SHASAVARI, H., Bull. Env. Pharmacol. Life Sci., 3, nr. 2, 2014, p. 169.

21. SAND, A., VYAS, A., GUPTA, A.K., Int. J. Biol. Macromol., 90, 2016, p. 37.

22. SUN, J.Y., ZHAO, X., ILLEPERUMA, W.R.K., CHAUDHURI, O., OH, K.H., MOONEY, D.J., VLASSAK, J.J., SUO, Z., Nature, 489, nr. 7414, 2012, p. 133.

Manuscript received: 13.12 .2018 